\title{
Evaluation of Chemical Warfare Agent Percutaneous Vapor Toxicity: Derivation of Toxicity Guidelines for Assessing Chemical Protective Ensembles
}

July 2003

Annetta Watson and Dennis Opresko

Veronique Hauschild

Approved for public release; distribution is unlimited. 


\section{DOCUMENT AVAILABILITY}

Reports produced after January 1, 1996, are generally available free via the U.S. Department of Energy (DOE) Information Bridge:

Web site: http://www.osti.gov/bridge

This report is approved for public release; distribution is unlimited. 
ORNL/TM-2003/180

\title{
Evaluation of Chemical Warfare Agent Percutaneous Vapor Toxicity: Derivation of Toxicity Guidelines for Assessing Chemical Protective Ensembles
}

\author{
Annetta Watson and Dennis Opresko \\ Life Sciences Division \\ Oak Ridge National Laboratory \\ Veronique Hauschild \\ Directorate of Health Risk Management \\ U.S. Army Center for Health Promotion and Preventive Medicine \\ Aberdeen Proving Ground, MD
}

July 2003

Prepared for the

U.S. Department of the Army

under

Interagency Agreement 2201-M135-A1

Prepared by the

Toxicology and Hazard Assessment Group

Life Sciences Division

OAK RIDGE NATIONAL LABORATORY

Oak Ridge, Tennessee 37831-6285

managed by

UT-BATTELLE, LLC

for the

U.S. DEPARTMENT OF ENERGY

under contract DE-AC05-00OR22725 



\section{CONTENTS}

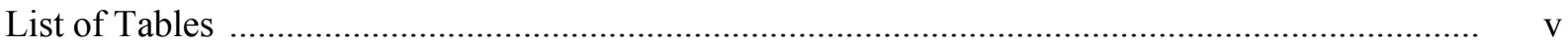

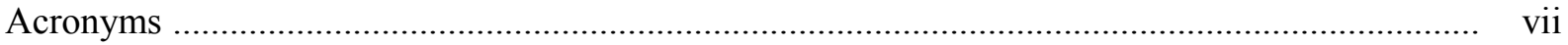

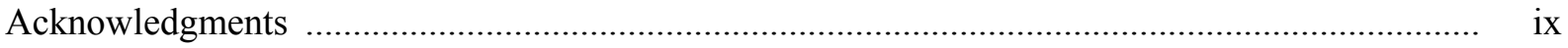

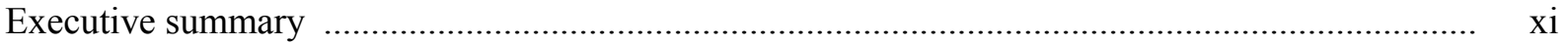

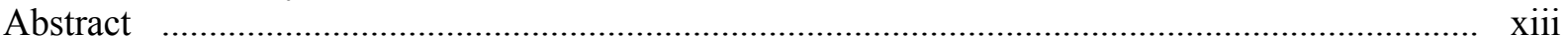

1. INTRODUCTION .................................................................................................... 1

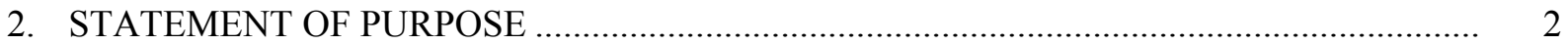

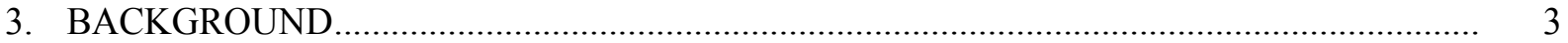

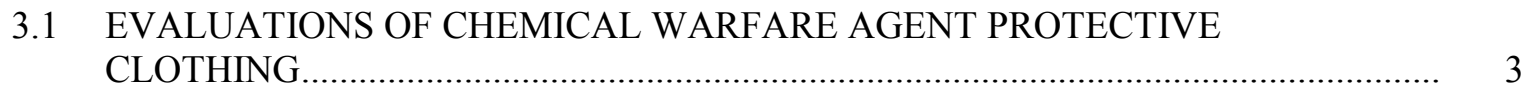

3.2 RECOMMENDATIONS OF THE MAN-IN-SIMULANT (MIST) REPORT

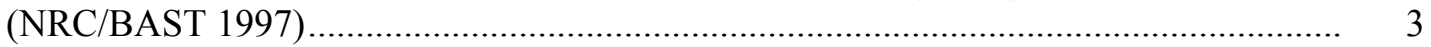

3.2.1 General Test Protocols .................................................................................. 4

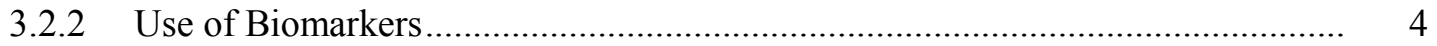

3.2.3 Use of Methyl Salicylate (MeS) as a Simulant for CPE Testing ......................... 4

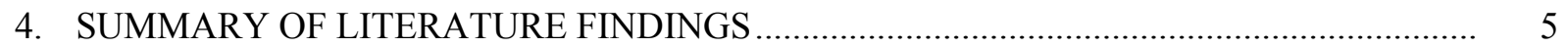

4.1 EFFECTS OF DERMAL EXPOSURES.......................................................... 5

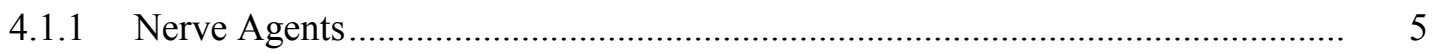

4.1.2 Vesicant Agents................................................................................. 5

4.2 ASSESSMENT OF REGIONAL SKIN VARIATION IN ABSORPTION; SUSCEPTIBILITY BY ANATOMIC SITE ................................................................... 6

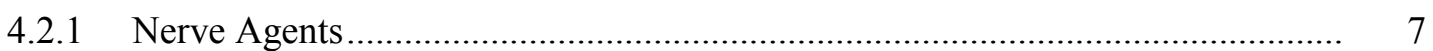

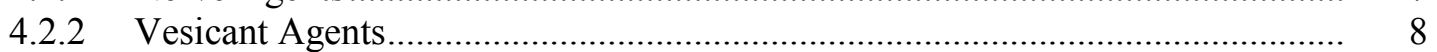

4.2.3 Body Region Variation in Susceptibility .................................................... 9

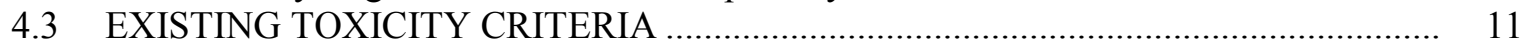

4.3.1 Acute Human Toxicity Estimates (NRC/COT 1997) ....................................... 11

4.3.2 Current Military Estimates (Grotte and Yang 2001) ...................................... 11

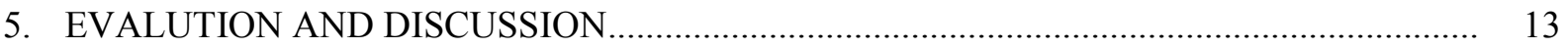

5.1 DETERMINING TOXICITY GUIDELINE CRITERIA FOR CIVILIAN CPE ............. 13

5.2 METHODS EVALUATED TO ESTIMATE MINIMAL EFFECT LEVELS ................ 13

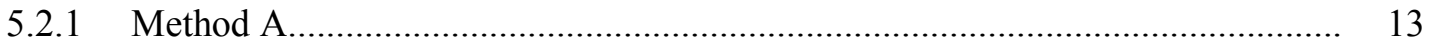

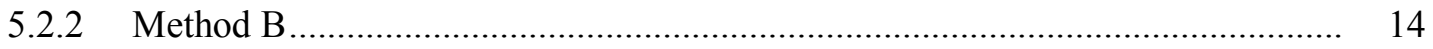

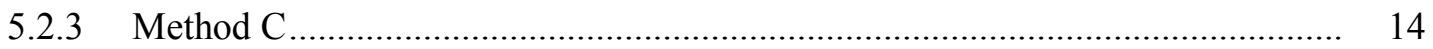

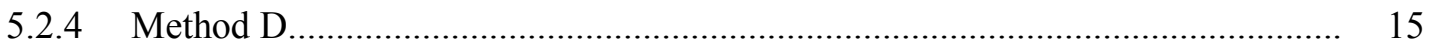

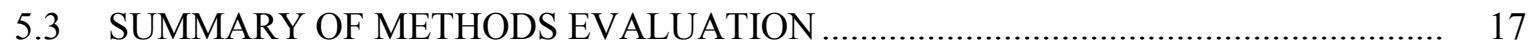

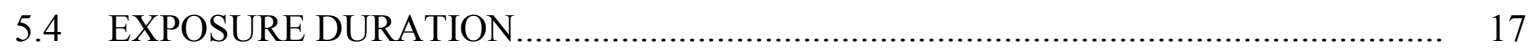

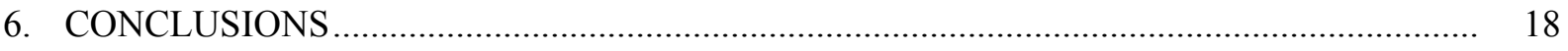

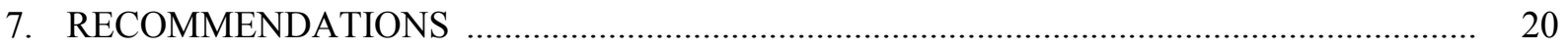

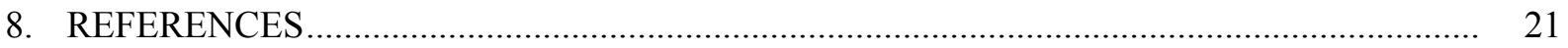





\section{TABLES}

ES-1. Recommended CPE percutaneous vapor toxicity test ranges for nerve agents (GA, GB, GD, GF, VX) and sulfur mustard (HD)

1 Distribution of mustard gas injuries on bodies of World War I casualties

2 Estimated relative rank in susceptibility of body regions to operationally adverse concentrations of $\mathrm{CW}$ agents

3 Existing interim military percutaneous vapor toxicity values for nerve agents (GA, GB, GD, GF, VX) and sulfur mustard (HD).

4 Percutaneous vapor estimated minimal effect $\left(\mathrm{EME}_{\mathrm{pv}}\right)$ toxicity values for nerve agents (GA, GB, GD, GD, VX) and sulfur mustard (HD)

5 Comparison among estimates of percutaneous vapor minimal effects levels; Method A, B, C, and D toxicity values for nerve agents (GA, GB, GD, GF, VX) and vesicants $(\mathrm{H} / \mathrm{HD}$ and $\mathrm{L})$.

6 Recommended CPE percutaneous vapor toxicity test ranges for nerve agents (GA, GB, GD, GF, VX) and sulfur mustard (HD) 



\section{ACRONYMS}

ACGIH

BAST

CBDCOM

CDC

$\mathrm{ChE}$

COT

CPE

$\mathrm{Ct}$

CW

CWA

DoD

ECt50

EME

GA

GB

GD

GF

$\mathrm{H}$

HD

IDA

IOM

L

LCt50

MeS

MIST

NIJ

NIOSH

NIST

NRC

NRL

OASD-CBD

OSRD

SBCCOM

SCBA

TLV
American Conference of Governmental Industrial Hygienists

Board on Army Science and Technology (NRC)

U.S. Army Chemical and Biological Defense Command (now SBCCOM)

Centers for Disease Control and Prevention

cholinesterase

Committee on Toxicology (NRC)

chemical protective ensemble

concentration (usually in $\mathrm{mg} / \mathrm{m}^{3}$ ) multiplied by time (usually in min) as an

estimate of cumulative exposure; $\mathrm{Ct}$ in units of $\mathrm{mg}-\mathrm{min} / \mathrm{m}^{3}$

chemical warfare

chemical warfare agent

U.S. Department of Defense

the statistically derived cumulative exposure $(\mathrm{Ct})$ causing a specifically

defined effect (E) in $50 \%$ of the exposed population

estimated minimal effect

dimethylamidocyanethylophosphate (a lethal organophosphorous chemical warfare agent, or "nerve" agent)

isopropyl methylphosphonofluoridate (a lethal organophosphorous chemical warfare agent, or "nerve" agent)

pinacolyl methylphosphonofluoridate (a lethal organophosphorous chemical warfare agent, or "nerve" agent)

O-cyclohexyl-methylfluorophosphonate (a lethal organophosphorous

chemical warfare agent, or "nerve" agent)

a vesicant (blister-causing) chemical warfare agent; Levinstein mustard;

sulfur mustard agent; non-distilled bis (2-chloroethyl) sulfide

a vesicant (blister-causing) chemical warfare agent; sulfur mustard agent;

distilled bis (2-chloroethyl) sulfide

Institute for Defense Analysis

Institute of Medicine

dichloro(2-chlorovinyl) arsine (the arsenical vesicant Lewisite)

statistically derived cumulative exposure $(\mathrm{Ct})$ resulting in lethality $(\mathrm{L})$ among

$50 \%$ of the exposed population

methyl salicylate

Man-in-Simulant Test Program

National Institute of Justice

National Institute for Occupational Safety and Health

National Institute of Standards and Technology

National Research Council

Naval Research Laboratory

DoD Office of the Assistant to the Secretary of Defense for Chemical and

Biological Defense

DoD Office of Scientific Research and Development

U.S. Army Soldier and Biological Chemical Command

self-contained breathing apparatus

threshold limit values 
USACHPPM U.S. Army Center for Health Promotion and Preventive Medicine

USDHHS

VX

U.S. Department of Health and Human Services

O-ethyl-S-(diisopropyl aminoethyl) methyl phosphonothiolate (a lethal

organophosphorous chemical warfare agent, or "nerve" agent) 


\section{ACKNOWLEDGMENTS}

This report was developed for, and in conjunction with, the U.S. Army Center for Health Promotion and Preventive Medicine, Aberdeen Proving Ground, MD, 21010-5403 under Military

Interdepartmental Purchase Request (MIPR) No. 2EYLR00323 and supported through funding provided by the National Institute of Justice (NIJ). The NIJ funding was provided through the National Institute of Standards and Technology (NIST) for the U.S. Army Soldier and Biological Chemical Command (SBCCOM) Interagency Agreement 02-03, "SBCCOM Support to NIST for Development of CB PPE/Detector Equipment Standards.”

The authors wish to acknowledge the sound technical advice and analyses provided by Robert Young and Tim Borges (Life Sciences Division, Oak Ridge National Laboratory).

Eugene Olajos and Paul Fedele [SBCCOM, Edgewood Chemical and Biological Center (ECBC), Aberdeen Proving Ground, MD] are acknowledged, with thanks, for their individual reviews and technical guidance to this report. Their contributions do not necessarily reflect an official position, and/or endorsement, of SBCCOM/ECBC.

The information and guidance provided by Tina Waters and Elaine Stewart-Craig and the other participating members of the Personal Protective Equipment Standards Team are also appreciated. 



\section{EXECUTIVE SUMMARY}

\section{PURPOSE}

This report provides suggested toxicity guidelines for assessment and selection of chemical protective ensembles (CPEs) to be used by civilian and military first responders operating in a chemical warfare agent vapor environment. The agents evaluated include the G-series and VX nerve agents, the vesicant sulfur mustard (agent HD) and, to a lesser extent, the vesicant Lewisite (agent L). The focus of this evaluation is percutaneous vapor permeation of CPEs and resulting skin absorption. A critical assumption underlying this evaluation is that first responders in an agent vapor atmosphere will be wearing self-contained breathing apparatus (SCBA) with full-face protection, and are thus adequately protected against inhalation or direct eye vapor exposure. Specific recommendations regarding toxicity criteria for SCBA/full-face protection are not addressed by this report. Exposures to liquids, aerosols, mixtures, or multiple agents are not addressed by this evaluation.

This analysis focused on estimating acceptable levels of chemical agent vapor permeation through a protective suit that would provide adequate health protection. The resulting toxicity guidelines are not intended to be the sole criteria from which to assess or select specific CPEs. This assessment notes that numerous other criteria are important to appropriate ensemble selection; for example, the CPE must also exhibit sufficient tear strength and flexibility, and meet other requirements critical to maintaining conduct of operations and mission capability. This assessment acknowledges the significance of these other necessary parameters that must also be factored into CPE selection.

\section{KEY CONCLUSIONS}

- Percutaneous vapor concentrations needed to produce adverse effects are significantly greater than inhalation vapor concentrations necessary to produce the same effect (for nerve agents especially, and sulfur mustard to a lesser extent). Thus, health-based inhalation and ocular toxicity guidelines used to test adequacy of respiratory protection would be substantially protective for percutaneous vapor effects from the same agent exposure. However, use of overly protective inhalation and ocular toxicity criteria for CPE evaluation may unnecessarily limit consideration of other critical CPE operational specifications. Application of separate vapor toxicity guidelines for percutaneous vapor absorption alone will ensure that CPE testing criteria include an appropriate balance of protection against agent percutaneous toxicity and other necessary operational requirements.

- Animal data indicate that there is not a significant difference in HD-induced skin damage between males and females; additionally, there do not appear to be substantial differences in cutaneous response on the basis of race (e.g., dark versus light skin).

- The most significant source of variation in susceptibility to percutaneous absorption of $\mathrm{CW}$ agents and their simulants is regional variation, relative to body site and skin thickness. Thus, selection of appropriately protective CPE designs and materials based on differential body region susceptibility to agent vapor exposures is appropriate.

- Assuming full-face protection, functional impairment will more rapidly follow from CW agent vapor exposure to the groin and scrotal area than from any other body region. This finding is particularly critical for consideration of operationally adverse exposures to agent sulfur mustard (HD). 
- Nerve agents are non-irritating to the skin, and generate no cutaneous injuries. Biomarkers for these agents may be used in conjunction with CPE permeation tests.

- Existing military percutaneous vapor toxicity estimates are not appropriate or adequate for assessment of CPE to be worn by the civilian workforce. Specifically, effects at the concentrationtime cumulative exposure toxicity estimates for expected severe effects in $50 \%$ of the exposed

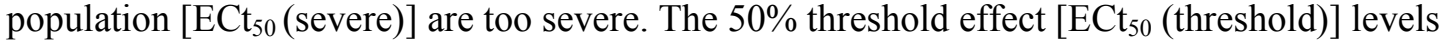
represent more reasonable health endpoints, but are still effect levels for $50 \%$ of those exposed, as opposed to levels protecting the majority (if not all) of the exposed population. In addition, existing estimates alone neither address database gaps and uncertainties, nor, more importantly, body region variation in absorption and susceptibility.

- Existing percutaneous toxicity data do not comprehensively support any clear, compound-specific, procedure for extrapolating or adjusting $\mathrm{ECt}_{50}$ (threshold) levels to lower population-effect percentages. The most reasonable approaches consider chemical- and effect-specific relationships.

- The state of the modeling tools presently available for percutaneous toxicity estimation is such that discrimination cannot be made between concentrations of concern for exposure durations between 30 and $50 \mathrm{~min}$.

\section{RECOMMENDATIONS}

- Selection of appropriately protective CPE designs and materials should be based on systems tests which focus on effective protection of the most vulnerable body regions (e.g., the groin area) as identified in this analysis.

- A range of agent-specific cumulative exposures (Cts), bounded by the $\mathrm{Ct}$ for percutaneous vapor estimated minimal effect $\left(\mathrm{EME}_{\mathrm{pv}}\right)$ and the threshold $\mathrm{ECt}_{01}$ estimate (see Table ES-1), can be used as decision criteria for $\mathrm{CPE}$ acceptance in conjunction with weighting consideration towards more susceptible body regions.

- Assumptions of exposure duration used in CPE certification should consider that each agentspecific percutaneous vapor cumulative exposure $\mathrm{Ct}$ for a given endpoint is a constant for exposure durations between $30 \mathrm{~min}$ and 2 hours.

Table ES-1. Recommended CPE percutaneous vapor toxicity test ranges for nerve agents (GA, GB, GD, GF, VX) and sulfur mustard (HD) (units in $\mathrm{mg}-\mathrm{min} / \mathrm{m}^{3}$ )

\begin{tabular}{|c|c|c|}
\hline Agent & $\begin{array}{l}\text { Upper end of range: } \\
\text { ECt }_{01} \text { (threshold) est. }\end{array}$ & $\begin{array}{l}\text { Lower end of range: }{ }^{b} \\
\text { Est. min. effect } \mathrm{Ct}\left(\mathrm{EME}_{\mathrm{pv}}\right)^{c}\end{array}$ \\
\hline GA & 685 & 333 \\
\hline GB & 411 & 180 \\
\hline GD & 123 & 45 \\
\hline GF & 103 & 45 \\
\hline VX & 4.1 & 4 \\
\hline HD (hot temp.) & 4.1 & 3 \\
\hline \multicolumn{3}{|c|}{$\begin{array}{l}{ }^{a} \text { Based on probit extrapolation of } \mathrm{ECt}_{50} \text { (threshold) from Grotte and Yang } 2001 \text { (see Table } 5 \text { in } \\
\text { this report). }\end{array}$} \\
\hline \multicolumn{3}{|c|}{${ }^{b}$ For susceptible body regions, e.g., groin, scrotal area. } \\
\hline${ }^{c}$ See Table 4 of $\mathrm{t}$ & or basis and derivation. & \\
\hline
\end{tabular}




\section{ABSTRACT}

Percutaneous vapor toxicity guidelines are provided for assessment and selection of chemical protective ensembles (CPEs) to be used by civilian and military first responders operating in a chemical warfare agent vapor environment. The agents evaluated include the G-series and VX nerve agents, the vesicant sulfur mustard (agent HD) and, to a lesser extent, the vesicant Lewisite (agent L). The focus of this evaluation is percutaneous vapor permeation of CPEs and the resulting skin absorption, as inhalation and ocular exposures are assumed to be largely eliminated through use of SCBA and full-face protective masks.

Selection of appropriately protective CPE designs and materials incorporates a variety of test parameters to ensure operability, practicality, and adequacy. One aspect of adequacy assessment should be based on systems tests, which focus on effective protection of the most vulnerable body regions (e.g., the groin area), as identified in this analysis. The toxicity range of agent-specific cumulative exposures (Cts) derived in this analysis can be used as decision guidelines for $\mathrm{CPE}$ acceptance, in conjunction with weighting consideration towards more susceptible body regions. This toxicity range is bounded by the percutaneous vapor estimated minimal effect $\left(\mathrm{EME}_{\mathrm{pv}}\right) \mathrm{Ct}$ (as the lower end) and the $1 \%$ population threshold effect $\left(\mathrm{ECt}_{01}\right)$ estimate.

Assumptions of exposure duration used in CPE certification should consider that each agent-specific percutaneous vapor cumulative exposure $\mathrm{Ct}$ for a given endpoint is a constant for exposure durations between 30 min and 2 hours. 



\section{INTRODUCTION}

The U.S. Army Center for Health Promotion and Preventive Medicine (USACHPPM) provides health and preventive medicine support to a variety of U.S. Army and U.S. Department of Defense (DoD) agencies by conducting health-risk assessments of chemical exposure scenarios. In addition, as the agency that directly supports the mission requirements of the Army Office of the Surgeon General, the USACHPPM identifies or, when necessary, develops, health guidelines and exposure limits for military-specific chemicals. Military-unique chemicals (such as the nerve and vesicant warfare agents) are military-unique and have historically not been considered to pose substantial civilian or civilian workforce hazards. As a result, civilian Federal agencies have provided little guidance relative to these compounds. Concern over scenarios involving potential civilian exposures, however, has increased in recent years. Consequently, various civilian Federal agencies have begun to coordinate or partner with experienced U.S. Army personnel and contractors in efforts to develop and identify appropriate civilian and worker guidelines, procedures, and associated resource requirements needed for response to a potential chemical terrorist event.

One such example is an ongoing partnership among the U.S. Army Soldier and Biological Chemical Command (SBCCOM), the Centers for Disease Control and Prevention (CDC), the National Institute for Occupational Safety and Health (NIOSH), the National Institute of Standards and Technology (NIST), and the National Institute of Justice (NIJ). This partnership is developing standards and guidelines for selection of appropriate personal protective equipment for use by civilian and/or military emergency workers responding to chemical, biological, radiological, or nuclear incidents. Recent history has generated a heightened awareness of resource requirements needed for appropriate response to a potential chemical terrorist event. Previous work and public meetings on this topic have considered respiratory protection standards and guidelines (67 FR 38127, 31 May 2002 and 67 FR 61108, 27 Sep 2002; USDHHS 2002a, b). The USACHPPM has participated in this effort, and coordinated the technical contract support provided by research staff of Oak Ridge National Laboratory (ORNL) Life Sciences Division. The USACHPPM concurs with the recommendations of this report from the Army's medical perspective relative to toxicity guidelines for the assessment and selection of clothing ensembles designed to protect emergency responders against percutaneous exposures to vapors of nerve and vesicant chemical warfare agents. This report is provided for consideration to ongoing partnerships as well as other agencies and organizations that may be addressing similar issues. 


\section{STATEMENT OF PURPOSE}

The principal objective of this report is to summarize and recommend toxicity guidelines for selection of chemical protective ensembles (CPEs) to be used by civilian and military first responders operating in an environment containing vapors of either nerve or vesicant chemical warfare agents. While this analysis recognizes that agent mixtures or multiple agents may be present in some threat environments, the current evaluation addresses potential exposures to single agents only. The agents under consideration include the G-series nerve agents and nerve agent VX; and the threat vesicant agents sulfur mustard (agent HD) and, to a lesser extent, Lewisite (agent L). Levinstein mustard (agent $\mathrm{H}$; approximately $70 \%$ bis 2-chloroethyl sulfide and $30 \%$ higher molecular weight polysaccharides) is not specifically addressed in this assessment. Nevertheless, it is reasonable to assume that guidelines developed for percutaneous exposure to vapors of distilled sulfur mustard (agent HD; $100 \%$ bis 2-chloroethyl sulfide) would be protective against exposures to Levinstein mustard. The focus of this evaluation is percutaneous vapor permeation through CPEs and exposure through the skin. It is assumed that first responders in an agent vapor atmosphere will be wearing SCBA with full-face protection. As a consequence, the eyes, nose, and mouth, as well as adjacent facial skin would be protected from vapor contact; therefore no inhalation or direct eye vapor exposure is assumed. Exposures to agent liquids, aerosols or mixtures are not addressed by this evaluation but may be considered at a later date. 


\section{BACKGROUND}

\subsection{EVALUATIONS OF CHEMICAL WARFARE AGENT PROTECTIVE CLOTHING}

During the U.S. history of offensive and defensive research programs evaluating chemical warfare agents, a number of chemical protective clothing studies have been performed. One of the largest and most extensive took place in the 1940s under the auspices of the Office of Scientific Research and Development (OSRD), and was conducted by two OSRD divisions; the National Defense Research Committee, and the Committee on Medical Research. These human-subject studies were the subject of the Institute of Medicine (IOM) report Veterans at Risk: The Health Effects of Mustard Gas and Lewisite (IOM 1993). The literature review of skin exposures to the vesicant agents sulfur mustard and Lewisite, and the characterization of toxic response contained in this volume, is both extensive and well researched. This IOM evaluation provides an excellent compilation that is useful to the current analysis and points out that there are no good experimental data to indicate substantial differences in cutaneous response on the basis of pigmentation associated with race [e.g., dark (Negro) versus light (Caucasian) skin] when skin is exposed to injurious concentrations of sulfur mustard. Of greatest significance is the site of skin exposure and skin thickness at that site; cutaneous response differences between individuals are no greater than those differences observed for different body regions of the same individual (IOM 1993).

A standing committee (Standing Committee on Program and Technical Review of the U.S. Army Chemical and Biological Defense Command) of the National Research Council Board on Army Science and Technology has performed a technical assessment of the Man-in-Simulant Test (MIST) program (NRC/BAST 1997). This evaluation makes a number of recommendations regarding the methods and logic of testing chemical protective ensembles, all of which are applicable to the current evaluation, and which will be incorporated into the present analysis. A key observation made by the Standing Committee was that the Army had heretofore "not established specific requirements for the chemical protective qualities of its ensembles" in part because "test results (protection factors) have never been correlated with biological endpoints," particularly with regard to the known variations in anatomic regional sensitivity to chemical warfare agents. As a consequence, the Standing Committee considered that developers of chemical protective ensembles have not previously been able to determine "how much protection is enough" (NRC/BAST 1997).

It is also noted that some weighting factor methods have been used to estimate average cumulative permeation of nerve and mustard agent over an entire protective ensemble for an average elapsed time (Belmonte 1998). The Expert Assistance (Equipment Test) Program has applied this latter method during recent tests of protective clothing for the U.S. Army Soldier and Biological Chemical Command (SBCCOM) Program Director for Domestic Preparedness.

\subsection{RECOMMENDATIONS OF THE MAN-IN-SIMULANT (MIST) REPORT (NRC/BAST 1997)}

As previously noted, the Standing Committee on Program and Technical Review of the U.S. Army Chemical and Biological Defense Command of the National Research Council Board on Army Science and Technology performed and published a technical assessment of the Man-in-Simulant Test (MIST) program (NRC/BAST 1997). Among their several tasks was (1) the preparation of a review of the test methods for the MIST program, (2) an evaluation of the use of biological markers to predict signs and symptoms associated with chemical warfare agent exposure, and (3) an examination of 
methyl salicylate (MeS) as a suitable simulant for MIST evaluations. Recommendations made by the Standing Committee to the Chemical and Biological Defense Command (CBDCOM; and by extension, to its successor agency the Soldier and Biological Defense Command, SBCCOM) are not unique to the MIST program for evaluating chemical protective ensembles (CPEs), and are highly applicable to the present analysis.

A general recommendation of the Standing Committee was the need for "a clear approach to establishing physiologic endpoints for protective ensemble testing." The current initiative will assist in meeting that need.

\subsubsection{General Test Protocols}

The NRC Standing Committee found that the MIST test protocol for examining CPEs would be improved by the addition of a preliminary screen that would eliminate those designs and individual ensembles exhibiting gross defects or breaches. The application of such a screening step to any program (not just MIST) of ensemble evaluation would allow greater efficiency, statistical power, and focus of scarce resources on appropriate systems tests.

\subsubsection{Use of Biomarkers}

The selection of cholinesterase inhibition as a biological marker for considering percutaneous regional variation to $\mathrm{CW}$ agent exposure was commended as a sound and innovative approach, but one that should not be used to estimate HD absorption. Compliance with the recommended testing and monitoring protocol development identified by the Standing Committee (NRC/BAST 1997) would resolve the Committee's reservations regarding the body region hazard analysis approach; e.g., establishing the relationship between ChE activity inhibition and nerve agent absorption through the skin; the relationship between percutaneous absorption of agent liquid and vapor; accounting for the "functional impairments" arising from sulfur mustard-induced lesions on sensitive body regions (groin and scrotal areas); and accounting for individual variations in sensitivity. There was no Standing Committee criticism of the relational comparison of regional susceptibility represented by body region hazard analysis.

\subsubsection{Use of Methyl Salicylate (MeS) as a Simulant for CPE testing}

The Standing Committee considered MeS to be an appropriate simulant for estimating agent transport into CPEs, but questioned using the results for making "biological interpretations" regarding CW agents. Please note that the studies of Riviere et al. (2001) and Duncan et al. (2002) were performed in the years following publication of NRC/BAST (1997), and members of the Standing Committee would not have had access to these more recent data comparing MeS and agent absorption through the skin of swine. 


\section{SUMMARY OF LITERATURE FINDINGS}

To further ongoing efforts in the development of updated standards for personal protective ensembles suitable for use by civilian and military first responders in a chemical warfare agent environment, the percutaneous toxicity of selected vesicants and nerve agent vapors has been examined. This memo report summarizes and recommends concepts appropriate as decision criteria for selection of candidate protective ensembles. This analysis assumes that first responders in an agent vapor atmosphere will be using, and wearing, SCBA with full-face protection. As a consequence, the eyes, nose, mouth and skin of the face would be protected from vapor contact, and no inhalation or direct eye vapor exposure is assumed. The key issues addressed by this evaluation include: (1) whether the CWA is damaging to the tissue at the site of contact; (2) the relevance of body region variation in absorption and susceptibility to agent toxicity, and (3) the determination of agent-specific toxicity criteria to be used in chemical protective suit penetration tests.

\subsection{EFFECTS OF DERMAL EXPOSURES}

\subsubsection{Nerve Agents}

"Nerve" agents are so named as a consequence of their anticholinesterase properties and subsequent adverse effects on both smooth and skeletal muscle function as well as the central nervous system. Nerve agent exposure also generates non-cholinergic effects, but their significance to the development of known clinical signs and symptoms has not been characterized. Nerve agents are non-irritating to the skin and generate no cutaneous injuries. The agents of concern for the present analysis are GA (tabun), GB (sarin), GD (soman), GF, and VX.

The earliest signs of dermal exposure are local, and include increased sweating and muscular fasciculations at the exposure site; these first effects may not be apparent for multiple hours postexposure (Sidell 1992, 1997). With increasing exposure and absorption, systemic effects such as nausea, vomiting, diarrhea and weakness are manifested; in cases of severe exposure, effects may progress to loss of consciousness, convulsions, paralysis, seizures, and respiratory arrest without manifestation of the intervening mild-to-moderate effects of localized sweating, etc. (Sidell 1992, 1997; Munro et al. 1994). Percutaneous vapor concentrations needed to produce adverse effects are significantly greater than inhalation vapor concentrations necessary to produce the same endpoint. For example, the estimated human $\mathrm{LCt}_{50}$ for agent GB vapor inhalation exposure is $35 \mathrm{mg}-\mathrm{min} / \mathrm{m}^{3}$, while the estimated human $\mathrm{LCt}_{50}$ for GB percutaneous vapor exposure is $12,000 \mathrm{mg}-\mathrm{min} / \mathrm{m}^{3}$ (Grotte and Yang 2001).

\subsubsection{Vesicant Agents}

The vesicant agent sulfur mustard (agent HD) is an alkylating compound and, as such, readily reacts with components of DNA, RNA and proteins. The chemical modifications that various biological molecules undergo through alkylation can result in severe disorganization of normal cell function. As a consequence, sulfur mustard is considered a cell poison, and is particularly toxic to mitotic cells. The skin epithelium is an important target because of its proliferating basal cell layer, although sulfur mustard produces cellular necrosis in any exposed cells at sufficient concentration. The biological activity of HD is characterized by a latent period of hours to days, and may be followed by inflammation, blistering, and local necrosis (depending on agent concentration and exposure duration). Toxicological effects are local at the point of agent contact with the skin, and begin to manifest (depending on exposure concentrations) within approximately 2-3 hours post-exposure (Dixon and 
Needham 1946; McNamara et al. 1975; Papirmeister et al. 1985, 1991; Smith and Dunn 1991; Watson and Griffin 1992; Smith 2002). The earliest manifestation is usually an itching rash at the point of contact, which may progress to swelling and erythema, and (sometimes large) blisters. Blisters are relatively painless for several days, but after 5-6 days, the pain becomes severe upon exposure to air or on contact; sensitivity of the blistered area can persist for weeks. Ulceration of the blister may or may not develop, but progression to an ulcer may require weeks to heal. As exposure to sulfur mustard also generates immunosuppression, infection of the blistered or ulcerated areas can be problematic. The severity of skin lesions experienced by exposed individuals is influenced by a number of factors independent of the exposure concentration, including anatomic and individual differences in skin sensitivity, skin thickness, ambient temperature, and amount of sweat on the skin (Watson and Griffin 1992; IOM 1993). Animal (guinea pig) experiments with same-site exposure to sulfur mustard vapor indicate that there are no significant discrepancies in severity of skin damage between males and females (Wormser et al. 2002). Evidence indicates that severe acute exposure is causal for increased pigmentation and depigmentation of exposed skin; such exposures can also lead to chronic skin ulceration, scar formation and the latent development of cutaneous cancers. It is thought that chronic exposure to minimally toxic (or subtoxic) doses could lead to abnormalities in skin pigmentation and cutaneous cancer (IOM 1993).

The vesicant agent Lewisite (L) is also a cellular poison, and reacts by altering and inactivating critical cellular enzyme systems. In marked contrast to sulfur mustard, Lewisite exposure is characterized by prompt onset of pain and/or stinging or burning sensations; necrosis is early and complete. Erythema is "immediate" (Smith and Dunn 1991), followed by the production of vesicles that coalesce to form larger blisters in approximately 2-3 hours (Goldman and Dacre 1989; Smith and Dunn 1991). Larger exposures result in agent penetration through subcutaneous tissue to muscle, with associated edema and necrosis (IOM 1993). In general, the cutaneous injuries of Lewisite exposure resemble those of HD, but develop more rapidly.

\subsection{ASSESSMENT OF REGIONAL SKIN VARIATION IN ABSORPTION; SUSCEPTIBILITY BY ANATOMIC SITE}

Numerous studies of dermatological disease treatment, transdermal drug delivery and the health hazards of contaminant exposure have documented site-specific body region differences in percutaneous absorption. Such regional variation is well known in humans and a number of animal species, particularly for pesticides used in agriculture (Wester and Maibach 1985,1989; Guy and Maibach 1985; Maibach et al. 1971; Moody and Franklin 1987; and others). A number of the pesticides for which regional variation has been determined are organophosphates, which exhibit the same anticholinesterase properties as nerve agents. As a consequence, the findings of regional variation studies performed with commercial organophosphates are relevant to the current analysis for nerve agents.

In vivo human studies of percutaneous absorption for the commercial organophosphorous insecticides malathion and parathion determined that the skin of the genital (scrotal) area exhibited a high penetration index, followed by the skin of the trunk and head (intermediate), and skin of the legs and arms (Maibach et al. 1971). Additional comparisons of scalp to forearm or forehead to forearm absorption of malathion and parathion indicates that OP pesticide absorption through the skin of these two regions of the head exceeds that of the forearm by an approximate factor of 4 (Wester and Maibach 1989). 


\subsubsection{Nerve Agents}

Most studies characterizing regional variation in permeability to nerve agents have been performed with liquid agent VX. The single percutaneous vapor exposure study in humans is the work documenting in vivo VX vapor exposures to the unclipped human arm or forearm published by Cresthull et al. (1963).

It is acknowledged that the chemical and physical properties of agent VX differ from those of the G-series nerve agents (Sidell 1997; Opresko et al. 1998; Munro et al. 1994, others) and that the agentspecific dose to attain the same endpoint may thus differ. Nevertheless, it is reasonable to assume that the relative differences in agent absorption exhibited between and among skin anatomic sites would be similar for all the nerve agents of interest, irrespective of agent-specific chemical and physical properties.

For a limited range of sublethal doses $(5-25 \mu \mathrm{g} / \mathrm{kg})$ of VX applied to 19 intact and equal-area skin sites on male human volunteers, Sim and Stubbs (1960) and Sim (1962) found that the head and neck areas exhibited the greatest skin absorption rates ("the most sensitive") as determined from serial blood cholinesterase determinations (RBC, whole blood and plasma cholinesterase) and associated evidence of clinical signs and symptoms. The head and neck areas tested included the back of the neck, forehead, top of the head, cheek, and ear. Sim (1962) observed that these critical areas required the most effective skin protection. Only slightly less "sensitive" than the head and neck areas were the groin, armpits and the area behind the knee (Table 6, p. 29, Sim 1962). The least permeable skin sites tested were those of hand, foot, knee (front) and elbow (exterior). Similar results were reported in the adjunct in vivo human percutaneous body region study of VX liquid performed by Feinsilver et al. (1965).

Craig et al. (1977) estimated the dermal absorption of liquid VX through the skin of the cheek and volar forearm of human volunteers at a range of environmental temperatures ranging from $-18^{\circ} \mathrm{C}$ to $46^{\circ} \mathrm{C}$; the amount of VX absorption was estimated from the observed degree of RBC-cholinesterase inhibition at various time periods post-exposure. At 3 hours post-exposure, the site differences in skin absorption were approximately 10 -fold, with the skin of the cheek being more permeable, regardless of temperature. For each skin site, differences in estimated VX absorption also varied approximately 10 -fold over the temperature range $\left(-18^{\circ} \mathrm{C}\right.$ to $\left.46^{\circ} \mathrm{C}\right)$ evaluated. The Craig et al. (1977) study also provided evidence that the skin can act as a storage depot for VX, with agent transfer from this depot promoted by increasing ambient temperature.

Duncan et al. (2002) have performed in vivo regional variation studies of liquid VX absorption on specific skin sites of domestic swine, a species with skin permeability similar to that of humans (Bartek et al. 1972; Dick and Scott 1991). Agent VX absorption was estimated by determination of blood cholinesterase (ChE) activity measured at various times post-exposure and expressed as a percentage of the control ChE activity. "Dramatic" site dependence was displayed in the rates and levels of $\mathrm{ChE}$ inhibition following same-dose topical application to skin of the ear or epigastrium. Of the two sites compared, the skin of the ear is far more permeable and allows a larger systemic dose to be delivered over a shorter time period (Duncan et al. 2002). The Duncan et al. (2001) work demonstrates that the total effective systemic dose is the collective result of independent exposures and consequent absorption from separate body regions through a process such as described by body region hazard analysis (please see NRC/BAST 1997 for background information on body region hazard analysis).

A number of available studies examining nerve agent percutaneous exposures to laboratory animals and humans add to the general knowledge of topical nerve agent exposures, but do not specifically 
evaluate regional variation. Included are the excised-tissue and in vivo guinea pig studies of liquid agent decontamination by van Hooidonk et al. (1983), the in vivo clipped rabbit abdominal skin penetration studies of liquid GB by Griesemer et al. (1958), the in vivo clipped rabbit abdominal skin penetration studies of GB vapor by McPhail and Adie (1960), the extensive review of animal literature by van Hooidonk (1978), and the in vivo VX vapor exposures to the unclipped human arm or forearm published by Cresthull et al. (1963).

\subsubsection{Vesicant Agents}

Body region variation in skin injury following exposure to vapors of sulfur mustard agent was evident during treatment of casualties during World War I (Gilchrist 1928) (Table 1).

The incidence of percutaneous injuries (excluding those to the eyes, face and respiratory tract, which under the current scenario would be protected with face and respiratory protection) in $6980 \mathrm{WW} \mathrm{I}$ casualties ranged from high values of $42.1 \%$ and $23.9 \%$ for the scrotum and anus, respectively, to relatively low values of $4.3 \%$ and $1.5 \%$ for the hands and feet, respectively. These operational data for unprotected military personnel indicate that the most vulnerable (dermal) areas to the vesicant action of sulfur mustard are not only moist and warm, but are also characterized by relatively thin skin (Smith and Dunn 1991; IOM 1993; Papirmeister et al. 1991).

During WWII, human military subjects participated in exposure chamber tests of treated clothing and respiratory protection devices under various concentrations of HD vapor (Heinen, et al. 1945; see also App. D "Excerpts from Chamber Tests with Human Subjects I, II and IX. Naval Research Laboratory (NRL) Reports Nos. P-22008 and P-2579" from IOM 1993). Heinen et al. (1945) point out that "the scrotal region was the most vulnerable area of the body" to sulfur mustard agent vapor, "and would be the most important area in the production of casualties," particularly when ambient temperatures were high $\left(\geq 85^{\circ} \mathrm{F}\right.$, or $\left.\geq 29.4^{\circ} \mathrm{C}\right)$. As the NRL tests included experimental use of full-face respiratory devices, distribution of the most severe injuries from the Heinen et al. study is roughly coincident with that exhibited by WWI casualties in Table 1 , when eye and respiratory tract protection are considered.

Note that IOM (1993) determined that the data presented in Heinen et al. (1945), and other related NRL reports, were collected without appropriate informed consent. Thus, the study protocols of the NRL tests do not conform to accepted guidelines concerning participation of human volunteers in research.

The Textbook of Military Medicine volume addressing chemical warfare agents (Sidell et al. 1997) generally concurs with the earlier characterizations of parameters governing skin susceptibility, and states that the "threshold amount of mustard vapor required to produce a skin lesion ... varies greatly depending on ... temperature, humidity, moisture on the skin, and exposure site on the body. Warm moist areas with thin skin such as the perineum, external genitalia, axillae, antecubital fossae, and neck are much more
Table 1. Distribution of mustard gas injuries on bodies of World War I casualties $^{a}$

\begin{tabular}{lc}
\hline \multicolumn{1}{c}{ Body part } & $\begin{array}{c}\text { Reported injuries } \\
\text { (\%) }\end{array}$ \\
\hline Eyes & 86.1 \\
Respiratory tract & 75.3 \\
Scrotum & 42.1 \\
Face & 26.6 \\
Anus & 23.9 \\
Back & 12.9 \\
Armpits & 12.5 \\
Neck & 12.0 \\
Arms & 11.7 \\
Chest & 11.5 \\
Legs & 11.4 \\
Buttocks & 9.8 \\
Abdomen & 6.4 \\
Thighs & 6.0 \\
Hands & 4.3 \\
Feet & 1.5 \\
\hline
\end{tabular}

${ }^{a}$ Percentage of mustard gas injuries to various body parts in 6980 World War I casualties (Gilchrist 1928; Blewett 1986). 
sensitive" (Sidell et al. 1997, p. 205). Data from casualties of the Iran-Iraq war are similar (Momeni et al. 1992; Augerson 2000).

Smith (2002) also points out that the "sensitivity of the groin and the need for elimination, even when wearing protective clothing, makes mustard injury in that area especially likely."

Data reported by a number of investigators, including an early vapor cup in vivo study by Nagy et al. (1946) on the skin of the human forearm, document the greater penetration of HD vapor at higher temperatures $\left(30-31^{\circ} \mathrm{C}\right.$ compared to $\left.21-23^{\circ} \mathrm{C}\right)$. General concurrence is noted from a less quantitative in vivo study of mustard vapor exposures to the human forearm published in the 1920s (Temple 1923) and performed at "winter" and "summer" ambient temperatures ("susceptibility of subjects was found to be greater in summer"). McNamara et al. (1975) and Papirmeister et al. (1991) also point out that both severity and "time to development" of mustard vapor lesions are influenced by humid, hot weather ("increases the effects").

Methyl salicylate (MeS) has long been considered an appropriate simulant for agent HD due to similar physical properties (water solubility, vapor pressure, and molecular weight) and fabric penetration characteristics, as well as its known safety for human topical use (Riviere et al. 2001). Further, its rapid hydrolysis and metabolism to salicylic acid and derivatives in the body of mammals allows ready monitoring of MeS in blood serum as a measure of systemic absorption (Duncan et al. 2002). Recent studies comparing percutaneous absorption and skin deposition of HD to MeS in the isolated perfused porcine skin flap has determined that the cutaneous disposition of HD and MeS are very similar (Riviere et al. 2001). The Riviere et al. (2001) work demonstrates that MeS simulates the HD dose acquisition process and strongly supports the use of $\mathrm{MeS}$ as a dermal simulant for agent $\mathrm{HD}$ exposure and hazard assessment. Topical application of MeS to 4 skin sites (skin of the ear, perineum, inguinal crease, epigastrium) on the domestic pig have identified the following rank order for MeS permeation: ear $>$ perineum $>$ inguinal crease $\geq$ epigastrium (Duncan et al. 2002). It is reasonable to consider the rank order of permeation would be similar for agent HD in contact with these same skin sites on the human body.

Lewisite, an organic arsenical with vesicant properties, is considered faster acting and more toxic than sulfur mustard at equivalent doses (see review by Watson and Griffin 1992). Nevertheless, much less is known about Lewisite than sulfur mustard regarding penetration through human skin (IOM 1993). Literature review has not identified any regional variation studies specific to Lewisite (IOM 1993; Watson and Griffin 1992). Until agent-specific data are available for Lewisite, it will be assumed that the body region variation in Lewisite absorption is similar to that documented for sulfur mustard.

\subsubsection{Body Region Variation in Susceptibility}

Body region variation in percutaneous absorption of $\mathrm{CW}$ agents and $\mathrm{CW}$ agent simulants has been documented with operational data from "live agent" use under battlefield conditions, the results of in vitro and in vivo experiments with agents and simulants, and literature summarizing percutaneous exposures to commercial organophosphorous pesticides. It is well understood that agent exposure at specific body regions results in more rapid and more severe physiological effects such as apnea (Duncan et al. 2002). In the case of the vesicant agent sulfur mustard (agent HD), a cell poison at the point of contact, physical impairment is also a function of regional skin variation in that the characteristic burns and blisters following HD exposure cause greater and more rapid debilitation when they develop at susceptible body regions (groin, scrotal area). As mentioned above, available literature supports the assumption of similar body region susceptibility following percutaneous absorption to the "other" vesicant agent, Lewisite (see IOM 1993; Watson and Griffin 1992). 
The threat nerve agents under consideration (the G-series nerve agents GA, GB, GD, GF; and nerve agent $\mathrm{VX}$ ) are non-irritating to the skin and generate no cutaneous injuries. For these compounds, body region variation in agent absorption governs identification of the critical body areas requiring the most effective skin protection to prevent development of significant systemic effects.

There is much convergence in the literature identification of specific body regions most susceptible to nerve and sulfur mustard agent absorption. It is acknowledged that the estimated agent exposure values considered critical will vary according to any number of assumptions used in developing exposure estimates. Nevertheless, the relative ranking of body region susceptibility provided by application of the body region hazard analysis logic as reviewed by the NRC/BAST (1997) seems sound. Further, while not absolute, the resulting ranking is supported by operational information on effects generated in the field as well as the susceptibility of certain body regions to incapacitating exposures at less than "battlefield" concentrations (IOM 1993, others). The NRC/BAST (1997) recommended that validation testing of the body region hazard analysis concept be performed via direct agent vapor exposure measurements with excised human skin. Perhaps partial validation could be attained in vivo with tests on the skin of swine. But until such validation can be performed, it seems prudent to employ the logic of relative ranking in body region variation as derived from NRC/BAST (1997; Table 2-3, p. 22, "Parameters for local body region hazard analysis") to estimate critical body regions requiring the most effective protection from operationally adverse agent concentrations. A summary is provided in Table 2. With application of the current study assumption of protected head and face (SCBA with full-face protection), the scrotal, ear, scalp and neck areas are the remaining critical regions requiring the most effective protection. The literature indicates that the entire groin area is especially susceptible to sulfur mustard injury and should be considered equivalent in sensitivity to the scrotal area.

Table 2. Estimated relative rank in susceptibility of body regions to operationally adverse concentrations of $\mathrm{CW}$ agents (derived from Table 2-3; NRC/BAST 1997) ${ }^{a, b}$

\begin{tabular}{lrr}
\hline \multicolumn{1}{c}{ Body region } & VX $^{b}$ & HD \\
\hline Scrotum & 1.0 & 1.0 \\
Chin and neck & 3.2 & 3.3 \\
Ears & 4.1 & 4.2 \\
Cheeks and neck & 4.3 & 4.4 \\
Nape (back of neck) & 15.4 & 15.7 \\
Scalp (top of head) & 6.8 & 6.9 \\
Abdomen & 19.9 & 20.4 \\
Back & 23.7 & 24.3 \\
Arms (lower, volar) & 25.0 & 25.6 \\
Arms (upper, dorsum) & 58.6 & 60.2 \\
Legs (plantar, lower) & 25.0 & 25.6 \\
Legs (plantar, upper) & 38.1 & 39.0 \\
Legs (dorsum, lower) & 58.6 & 60.2 \\
Legs (dorsum, upper) & 58.6 & 60.2 \\
Knees (front) & 63.8 & 65.4 \\
\hline
\end{tabular}

${ }^{a}$ Ranking relative to scrotal dose in $\mu \mathrm{g} / \mathrm{kg}$ (VX; estimated to cause $70 \%$ depression in RBC-ChE) or scrotal cumulative exposure in mg$\mathrm{min} / \mathrm{m}^{3}$ (HD; estimated to cause local severe burns), with value of 1 (scrotum) indicating most susceptible body region. Source: Fedele and Nelson (1996) as cited in NRC/BAST 1997.

${ }^{b}$ Given the state and extent of existing percutaneous toxicity data, it seems reasonable to assume that the relative ranking exhibited by nerve agent VX would be shared by the G-series agents. Agentspecific vapor concentrations considered operationally adverse would vary per individual chemical and physical properties, etc. 


\subsection{EXISTING TOXICITY CRITERIA}

As this report is focusing on percutaneous vapor exposures, only those criteria relevant to the percutaneous absorption of agent vapors are described here.

\subsubsection{Acute Human Toxicity Estimates (NRC/COT 1997)}

In 1996, The National Research Council Committee on Toxicology established the Subcommittee on Toxicity Values for Selected Nerve and Vesicant Agents to evaluate the scientific validity of proposed military estimates of human toxicity for the chemical warfare agents GA, GB, GD, GF, VX and HD. The Subcommittee was chaired by Dr. Loren Koller, DVM, and was charged with examining the decision protocols and data quality for a variety of acute toxicological endpoints (ranging from mild to lethal) and different exposure routes, the derivation methods, and the underlying assumptions on which the derivations were based. The Subcommittee findings and recommendations were published in their summary report Review of Acute Human-Toxicity Estimates for Selected Chemical-Warfare Agents, in 1997 (NRC/COT 1997).

In general, the Subcommittee noted the limited database and recommended that the Army establish an expert panel to determine a research strategy for addressing key data gaps. The Subcommittee also recommended that human toxicity estimates be based on more current decision logic such as structureactivity relationships, uncertainty factors and experimental results with in vitro systems. However, the Subcommittee recognized that "best estimates" were needed to protect military personnel, and therefore made detailed and agent-effect-specific $\mathrm{Ct}$ recommendations for inhalation (vapor) and percutaneous (vapor and liquid) exposures. The evaluation indicated that some of the proposed military estimates were scientifically valid, others could only be considered interim pending additional data, some should be lowered, while others should be raised. Because of the data limitations and fact that the estimates were designed for healthy male soldiers, the Subcommittee also stated that the proposed human-toxicity estimates "must not be used for civilians." (NRC/COT 1997).

\subsubsection{Current Military Estimates (Grotte and Yang 2001)}

As a result of the NRC/COT (1997) report, the DoD is pursuing initiatives to address scientific data gaps. However, as the military has ongoing needs for various applications of $\mathrm{CW}$ agent toxicity criteria, the Office of the Assistant to the Secretary of Defense for Chemical and Biological Defense endorsed a policy in December 2001 (OASD-CBD 2001) that provides interim toxicity estimates for application to threat and CONOPS planning, active and passive defense, counter-force operations, and other military needs where the impact of chemical weapon use is critical. These interim toxicity values are documented in a report by the Institute for Defense Analysis (IDA), referred to as the "IDA

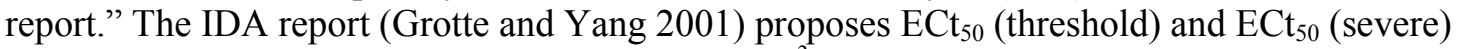
cumulative exposures estimates (units of $\mathrm{mg}$ - $\mathrm{min} / \mathrm{m}^{3}$ ) for acute effects and short-term (30-min) percutaneous exposures (see Table 3 ); the report indicates that the accuracy of extrapolations to exposure times beyond two hours is unknown. As defined in Grotte and Yang (2001), the percutaneous vapor "threshold" for nerve agents refers to "a slight ChE inhibition," and is thus a systemic effect endpoint. Threshold effects for HD are defined as "the midpoint of the dosage range at which effects begin to occur in the sample population" (Grotte and Yang 2001, page 7, footnote to Tables 1-6); however, threshold effects are not specifically characterized. 
These percutaneous vapor values are for unclothed persons $(70-\mathrm{kg}$ males) only. For nerve agents, it is assumed that soldiers are masked and possess full eye protection (Grotte and Yang 2001). Grotte and Yang (2001) are silent on the topic of body region variation in skin absorption and susceptibility. Thus it is not clear if the above estimates of "threshold" cumulative exposure are sufficiently protective for sensitive body regions, such as the groin and scrotum (especially for sulfur mustard). However, because the IDA values are reported to be for unclothed persons, (and assuming that unclothed means complete nudity), inference indicates that the IDA estimates would incorporate exposure to the most susceptible body regions. Therefore, the assumption could be made here that the IDA values are protective for the most susceptible body regions.
Table 3. Existing interim military percutaneous vapor toxicity values for nerve agents (GA, GB, GD, GF, VX) and sulfur mustard (HD) (units in $\left.\mathrm{mg}-\mathrm{min} / \mathrm{m}^{3}\right)^{a}$

\begin{tabular}{lcc}
\hline Agent & $\begin{array}{c}\mathbf{E C t}_{\mathbf{5 0}} \\
\text { (severe) }\end{array}$ & $\begin{array}{c}\mathbf{E C t}_{\mathbf{5 0}} \\
\text { (threshold) }\end{array}$ \\
\hline GA & 12000 & 2000 \\
GB & 8000 & 1200 \\
GD & 2000 & 300 \\
GF & 2000 & 300 \\
VX & 25 & 10 \\
HD (moderate temp.) & $500^{b}$ & 50 \\
HD (hot temp.) & $200^{b}$ & 25 \\
\hline
\end{tabular}

${ }^{a}$ J. H. Grotte and L. I. Yang, Report of the Workshop on Chemical Agent Toxicity for Acute Effects, Institute for Defense Analyses, 11-12 May, 1998. IDA Document D-2176, Institute for Defense Analyses (IDA), Alexandria, Va. (June 2001). For 30-min exposures to unclothed 70-kg male soldiers and acute effects following vapor exposure to undiluted agent in military scenarios; not for female military personnel or civilians, or exposures to modified versions of these agents. For nerve agents, percutaneous exposures are for masked soldiers with eye protection. "Threshold" for nerve agents refers to "a slight ChE inhibition." Threshold effects for HD are defined as "the midpoint of the dosage range at which effects begin to occur in the sample population"; however, specific effects are not characterized.

${ }^{b}$ Vesication. 


\section{EVALUATION AND DISCUSSION}

\subsection{DETERMINING TOXICITY GUIDELINE CRITERIA FOR CIVILIAN CPE}

The purpose of this evaluation is to identify criteria for evaluating CPEs to be used by the civilian workforce during domestic/homeland defense response activities. The intent behind such criteria should be consistent with general occupational health standards. Specifically the Occupational Safety and Health Act of 1970 [Section 2(b)] cites the Act's purpose to "assure as far as possible every working man and woman in the Nation safe and healthful working conditions ... by setting standards that [Section 6(b)(5)] most adequately assures, to the extent feasibly possible, on the basis of best available evidence that no employees will suffer material impairment of health"(U.S. Congress 1970). Even so, $100 \%$ protection of the worker population against all effects is not always considered feasible given the wide degree of variation in susceptibility, as demonstrated by various occupational threshold limit values (TLVs) (ACGIH 2000). Threshold Limit Values are described as concentrations to which "nearly all workers may be exposed ... without adverse effects" (ACGIH 2000). With this in mind, the goal of the present analysis is to provide scientifically based minimal effects levels that are reasonably protective of the civilian workforce against any adverse effect.

As indicated previously, NRC/COT (1997) pointed out that the human data forming the basis for the military toxicity estimates (as later presented in Grotte and Yang 2001) varied both in quality and degree of confidence warranted for such estimates. An example is the estimate for sulfur mustard (HD); the NRC/COT (1997) judged that the human data forming the basis for the threshold estimate were not sufficiently characterized in the source report (PCS 1946) "to allow for full evaluation" and confidence. The severe-effects estimates for sulfur mustard were clearly derived from "man-break" data for skin burns and blisters. "Man-break" tests were those deliberately designed to determine the agent concentrations and exposure durations sufficiently injurious to make exposed individuals unfit for duty. The NRC/COT (1997) reviewers considered that evaluation of experimental, low-vapor concentration data would be required before adequate confidence in the estimates could be attained, and recommended that percutaneous threshold $\mathrm{ECt}_{50}$ values (for both threshold and severe effects from HD) should be considered interim values only until improved data were available. In addition, the $\mathrm{NRC/COT} \mathrm{(1997)} \mathrm{noted} \mathrm{that} \mathrm{the} \mathrm{proposed} \mathrm{estimates} \mathrm{are} \mathrm{limited} \mathrm{to} \mathrm{applications} \mathrm{involving} \mathrm{male} \mathrm{military}$ personnel (excluding female military personnel and no civilians of either gender).

Given the caveats to existing toxicity estimates as described above, the current analysis considered a number of alternatives by which to estimate a minimal effect level suitable for civilian emergency workers, and to thus recommend a cumulative percutaneous exposure range over which $\mathrm{CPE}$ ensembles could be evaluated. Because existing percutaneous toxicity data and estimates do not comprehensively support any clear, compound-specific, procedure for estimating minimal effects, some existing methods used for inhalation vapor toxicity estimation were considered for comparative purposes. Ultimately, however, methods that address chemical- and effect-specific relationships, or which consider agent-specific distributions (as defined by the probit slope) were determined to be most defendable. The various methods developed and considered are outlined below:

\subsection{METHODS EVALUATED TO ESTIMATE MINIMAL EFFECT LEVELS}

\subsubsection{Method A}

It is known from $\mathrm{NRC/COT} \mathrm{(2001)} \mathrm{that} \mathrm{an} \mathrm{LC}_{01}$ can be approximated from an experimentally derived $\mathrm{LC}_{50}$ when certain parameters can be met by the experimental data: all experimental exposure levels 
should have caused some lethality, there is a steep dose-response curve, and data characterizing response at the lower part of the dose-response curve are available for examination. If these conditions can be met, then the $\mathrm{LC}_{50}$ can be divided by a single specific factor (typically a factor of " 3 ," based on knowledge that the average factor documented in the experimental literature for inhalation toxicity experiments is approximately 2 , with a 90th percentile of 2.9 and a 95th percentile of 3.5; range of 1.1 to 6.5) (NRC/COT 2001). However, this method has only been documented for the lethality endpoint; there is no comparable approximation procedure of division by a single specific factor documented for adjustment from $\mathrm{ECt}_{50}$ determinations. In addition, the $\mathrm{NRC}$ documents this method for vapor inhalation only, and does not address percutaneous toxicity. Though this approach would to some degree reflect agent- and endpoint-specificity, the required statistical and physiological basis for application of this approach are not met for percutaneous toxicity estimates. Thus, Method A is not a recommended or preferred approach, but is included here for comparison.

\subsubsection{Method B}

Another approach evaluated was to apply the standard default uncertainty factor (UF) for intraspecies variability to respiratory toxicants in humans (equal to a value of "10"; $\mathrm{NRC/COT} \mathrm{2001)} \mathrm{to} \mathrm{the} \mathrm{ECt} 50$ values from Grotte and Yang (2001) for the purpose of approximating a minimal effect level. The use of uncertainty factors in estimating percutaneous toxicity endpoints is not well characterized, and the literature review performed during the present analysis could find no precedent for such a procedure. In particular, as has been previously noted in this analysis, there appears to be limited intraspecies variability for percutaneous absorption. The critical source of variability is attributed to individual differences in susceptibility relative to body site and skin thickness. For this reason, and because Method B does not consider agent- or endpoint-specificity, this method is not a recommended or preferred approach.

\subsubsection{Method C}

The third approach evaluated provides some degree of compound- and endpoint-specificity, and maintains consistency with recent previous estimates for these agents (Grotte and Yang 2001). For each chemical warfare agent under consideration, the IDA Report presents two values for percutaneous $\mathrm{ECt}_{50}$; one each for "severe" and "threshold" effects. For the nerve agents, "severe" effects are defined as "systemic, similar to lethal effects," while "threshold" refers to "a slight ChE inhibition." For sulfur mustard agent HD, "severe" effects consist of "vesication," while "threshold" effects "are defined as the midpoint of a dosage range at which effects begin to occur." The difference in $\mathrm{ECt}_{50}$ values between "severe" and "threshold" results in a ratio that is both compound- and endpoint-specific (e.g., for agent GA, the difference between "severe" and "threshold" from 12000 to $2000 \mathrm{mg}-\mathrm{min} / \mathrm{m}^{3}$, results in a ratio of 6 ; see Table 3). This ratio is then applied to the threshold $\mathrm{ECt}_{50}$ as a means of estimating a minimal effect level (e.g., one-sixth of $2000 \mathrm{mg}-\mathrm{min} / \mathrm{m}^{3}$ is $333 \mathrm{mg}-\mathrm{min} / \mathrm{m}^{3}$, rounded to the nearest whole number). Applying the same procedure for agents GB, GD, GF, VX and $\mathrm{HD}$ results in the ratios and the percutaneous vapor "estimated minimal effect" or "EME summarized in Table 4. 
Table 4. Percutaneous vapor estimated minimal effect $\left(\mathrm{EME}_{\mathrm{pv}}\right)$ toxicity values for nerve agents (GA, GB, GD, GF, VX) and sulfur mustard (HD) (units in mg-min $\left./ \mathrm{m}^{3}\right)^{a}$; Method C

\begin{tabular}{|c|c|c|c|c|}
\hline Agent & $\begin{array}{c}\mathbf{E C t}_{50} \\
{\text { (threshold })^{a}}^{a}\end{array}$ & $\begin{array}{l}\text { Basis for } \mathrm{ECt}_{50} \\
\text { (threshold) effect }\end{array}$ & $\begin{array}{c}\text { Ratio } \\
\text { threshold: } \\
\text { severe }^{b}\end{array}$ & $\begin{array}{r}\text { Est. min. } \\
\text { effect }^{b} \mathrm{Ct} \\
\left(\mathrm{EME}_{\mathrm{pv}}\right)\end{array}$ \\
\hline GA & 2000 & $\begin{array}{l}\text { ChE activity inhibition but no } \\
\text { performance degradation; } \\
\text { human data }^{c}\end{array}$ & $1: 6$ & 333 \\
\hline GB & 1200 & $\begin{array}{l}\text { Sweating, ChE activity } \\
\text { inhibition; human data }^{c}\end{array}$ & 1: 6.7 & 180 \\
\hline GD & 300 & Relative potency from GB data ${ }^{c}$ & 1: 6.7 & 45 \\
\hline GF & 300 & Assume GF equipotent to GD & 1: 6.7 & 45 \\
\hline $\mathrm{VX}$ & 10 & $\begin{array}{l}<50 \% \mathrm{ChE} \text { activity inhibition; } \\
\text { extrap. from human exposure to } \\
25.6 \mathrm{mg}-\mathrm{min} / \mathrm{m}^{3} ; \text { low } \\
\text { confidence in data }\end{array}$ & $1: 2.5$ & 4 \\
\hline $\begin{array}{l}\mathrm{H} / \mathrm{HD}(\mathrm{L})^{d} \\
\text { (hot temperature) }\end{array}$ & 25 & $\begin{array}{l}\text { Less than Ct required to } \\
\text { generate mild erythema; human } \\
\text { data }^{e}\end{array}$ & $1: 8$ & 3 \\
\hline
\end{tabular}

${ }^{a}$ Grotte, JH and LI Yang, 2001. Report of the Workshop on Chemical Agent Toxicity for Acute Effects. Institute for Defense Analyses, 11-12 May, 1998. IDA Document D-2176, Institute for Defense Analyses (IDA), 1801 N. Beauregard St., Alexandria, VA (June 2001). For $30 \mathrm{~min}$ exposures to unclothed $70 \mathrm{~kg}$ male soldiers and acute effects following exposure to undiluted agent in military scenarios; not for female military personnel or civilians, or exposures to modified versions of these agents. For nerve agents, percutaneous exposures are for masked soldiers with eye protection.

${ }^{b}$ Estimated from the ratio between severe and threshold percutaneous $\mathrm{ECt}_{50}$ values (see Table 3 ) for each agent as presented in Grotte and Yang (2001); see text for logic and details.

${ }^{c}$ Effect evaluations from National Research Council, Committee on Toxicology (NRC/COT) 1997. Review of Acute Human-Toxicity Estimates for Selected Chemical-Warfare Agents, Subcommittee on Toxicity Values for Selected Nerve and Vesicant Agents, Committee on Toxicology, National Research Council. National Academy Press, Washington, D.C.

${ }^{d}$ As stated earlier, until more agent-specific data become available, the current analysis assumes that toxicological endpoints developed for vesicant agent HD will also apply to vesicant agent L (Lewisite).

${ }^{e}$ PCS 1946 as cited in Papirmeister et al. 1991. Threshold for non-disabling signs and symptoms in sulfur-mustard exposed adult male military personnel is $50 \mathrm{mg}-\mathrm{min} / \mathrm{m}^{3}$.

\subsubsection{Method D}

A fourth approach, which is also compound- and endpoint-specific, considers the application of probit slopes to developing percutaneous vapor estimates for endpoints other than $\mathrm{ECt}_{50}$. As discussed earlier, the Grotte and Yang (2001) report provided percutaneous toxicity values for several endpoints: $\mathrm{LCt}_{50}, \mathrm{ECt}_{50}$ (threshold) and $\mathrm{ECt}_{50}$ (severe), rounded to the nearest associated power of 10, along with the probit slope values (rounded to the nearest whole number). In the current analysis, standard methods have been employed to extrapolate percentile values towards the lower end of the log-normal $\mathrm{ECt}_{50}$ (threshold) distribution curve as a means to estimate minimal effects levels. Statistically, values below the 16th percentile have low reliability, but such values are nevertheless useful for purposes of comparative estimation. As a consequence, the 1 and 16th percentile estimates for ECt (threshold) have been calculated for the G-series nerve agents, nerve agent VX, and vesicant agent $\mathrm{HD}$ as an approach to estimating a minimal effect level. (See Table 5). 
Method D calculations were performed using the following assumptions concerning the $\mathrm{ECt}_{50}$ and the probit slope:

1. That for any fixed variable for concentration, there was a corresponding random variable for percent affected containing a probability distribution with a finite mean and variance.

2. That all of the determined percent affected were statistically independent from each other.

3. That the average value for percent affected is a straight-line function of concentration.

4. That the variances for concentration and percent affected were statistically equal.

5. That for any fixed value for concentration, there was a normal distribution for percent affected.

6. That the intercept used in the calculation was equivalent to the difference between the calculated $50 \%$ response and that provided in the IDA report.

The following limitations also apply to the calculated results:

1. The probit distribution was derived from a common error function derived from $50 \%$ adjusted to a slope of 5.0.

2. A normally distributed population is assumed with the results sensitive to outlying points.

3. Most importantly, the frequency distribution of each point along the line becomes more asymptotic as it approaches the extremes of the range. That is to say that in the probit range of 16 to $84 \%$ [those values associated with 1 standard deviation (SD)] the error in the line changes gradually. Beyond this range, the error changes ever more rapidly (Kleinbaum et al. 1988). As a consequence, the confidence limit in a $1 \%$ value is broad. Statistically, the most confidence in the results would be for the interval between 16 and $84 \%$.

Table 5. Comparison among estimates of percutaneous vapor minimal effects levels; Method A, B, C, and $D$ toxicity values for nerve agents (GA, GB, GD, GF, VX) and vesicants (H/HD and L) (units in $\mathrm{mg}-\mathrm{min} / \mathrm{m}^{3}$ )

\begin{tabular}{|c|c|c|c|c|c|c|}
\hline \multirow[b]{2}{*}{ Agent } & \multirow[b]{2}{*}{$\begin{array}{l}\text { ECt }_{50} \\
(\text { threshold })^{a}\end{array}$} & \multirow{2}{*}{ 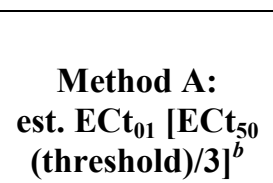 } & \multirow{2}{*}{$\begin{array}{c}\text { Method B: } \\
\text { UF approach } \\
\text { [ECt }_{\mathbf{5 0}} \\
{\text { (threshold) } / \mathbf{1 0}]^{c}}^{c}\end{array}$} & \multirow{2}{*}{$\begin{array}{l}\text { Method C: } \\
\text { ratio-based } \\
\text { EME }_{\mathrm{pv}} \mathrm{Ct}^{d}\end{array}$} & \multicolumn{2}{|c|}{$\begin{array}{l}\text { Method D: probit } \\
\text { extrapolations }\end{array}$} \\
\hline & & & & & $\begin{array}{c}\text { ECt }_{01} \\
\text { (thresh.) }\end{array}$ & $\begin{array}{c}\mathrm{ECt}_{16} \\
\text { (thresh.) }\end{array}$ \\
\hline GA & 2000 & 667 & 200 & 333 & 685 & 1265 \\
\hline GB & 1200 & 400 & 120 & 180 & 411 & 759 \\
\hline GD & 300 & 100 & 30 & 45 & 123 & 205 \\
\hline GF & 300 & 100 & 30 & 45 & 103 & 190 \\
\hline VX & 10 & 3.3 & 1 & 4 & 4.1 & 6.8 \\
\hline $\begin{array}{l}\mathrm{H} / \mathrm{HD}(\mathrm{L}) \\
\text { (hot temp) }\end{array}$ & 25 & 8.3 & 2.5 & 3 & 4.1 & 11.7 \\
\hline \multicolumn{7}{|c|}{${ }^{a}$ From Grotte and Yang (2001). } \\
\hline \multicolumn{7}{|c|}{$\begin{array}{l}{ }^{b} \text { Required statistical and physiological basis for application of this approach cannot be met for percutaneous toxicity } \\
\text { estimation. Not recommended or preferred. }\end{array}$} \\
\hline \multicolumn{7}{|c|}{${ }^{c}$ No agent- or endpoint-specificity. Not recommended or preferred. } \\
\hline \multicolumn{7}{|c|}{${ }^{d}$ Compound- and endpoint-specific; maintains consistency with Grotte and Yang (2001). Recommended and preferred. } \\
\hline
\end{tabular}




\subsection{SUMMARY OF METHODS EVALUATION}

With full acknowledgement of the described limitations, it is nevertheless useful to compare various estimates derived from the four methods (A, B, C, D) described above. It is particularly interesting to note that all methods yield estimates of minimal effect levels that are within the same order of magnitude. For all agents, the $\mathrm{EME}_{\mathrm{pv}}(\mathrm{Method} \mathrm{C})$ provided middle ground values for the range of estimates. For threshold effects, the $\mathrm{EME}_{\mathrm{pv}} \mathrm{Ct}$ for $\mathrm{G}$-agents is less than $50 \%$ of the probit-estimated $\mathrm{ECt}_{01}$ and approximately four times less than the $\mathrm{ECt}_{16}$ (Method D), while the $\mathrm{EME}_{\mathrm{pv}}$ for agent $\mathrm{VX}$ is approximately equal to the estimated $\mathrm{ECt}_{01}$ (and approximately $60 \%$ of the $\mathrm{ECt}_{16}$ ). For sulfur mustard agent $\mathrm{HD}$, the $\mathrm{EME}_{\mathrm{pv}} \mathrm{Ct}$ for high temperatures $\left(3 \mathrm{mg}-\mathrm{min} / \mathrm{m}^{3}\right)$ is only slightly less (and likely not significantly so) than the estimated "high-temperature" $\mathrm{ECt}_{01}\left(4.1 \mathrm{mg}-\mathrm{min} / \mathrm{m}^{3}\right.$; though approximately 4 times less than the $\mathrm{ECt}_{16}$ ). Methods $\mathrm{A}$ and $\mathrm{B}$, though the least rigorous and least preferred of the approaches, exhibit relative consistency with the results from Methods $\mathrm{C}$ and $\mathrm{D}$. This comparison provides added confidence to the overall analysis.

Because they are bounded by the other estimates and are compound- and endpoint-specific, the $\mathrm{EME}_{\mathrm{pv}}$ $\mathrm{Ct}$ values derived from Method $\mathrm{C}$ are selected as the 'best' toxicity guideline criteria of those examined for $\mathrm{CPE}$ testing. These toxicity guidelines provide protective criteria for the emergency response user community in that they incorporate consideration of particularly susceptible body regions. To provide a range of toxicity guideline criteria, such as to establish less stringent criteria for assessing CPE protection of less susceptible body regions, the $\mathrm{ECt}_{01}$ (threshold) estimates derived from Method D provide a reasonable high end of the minimal effect range.

\subsection{EXPOSURE DURATION}

In addition to estimating a minimal effect toxicity $\mathrm{Ct}$, the concept of applying this toxicity estimate to a specified duration of time was assessed. Grotte and Yang (2001) indicate that the percutaneous vapor estimates summarized in their report are for 30-min exposures to individuals without clothing (nude), and that "accuracy of extrapolation beyond 2 hours is unknown." After examining the same parent data set as utilized by Grotte and Yang (2001), NRC/COT (1997) documents assumptions of 30- to 50-min exposure durations and light clothing for percutaneous vapor exposure estimates (when compared to Grotte and Yang 2001, values in NRC/COT 1997 are same or similar). It would appear that the state of the modeling tools available for percutaneous toxicity estimation is such that discrimination cannot be made between concentrations of concern for exposure durations between 30 and $50 \mathrm{~min}$. Therefore, for a given endpoint and scenario, it may be reasonable to assume an agentand endpoint-specific constant $\mathrm{Ct}$ for exposure durations between 30 min and 2 hours. Further, this constant $\mathrm{Ct}$ should be equal to the 30-min $\mathrm{Ct}$ for that agent and $\mathrm{EME}_{\mathrm{pv}}$. Thus, the 30 -min $\mathrm{EME}_{\mathrm{pv}}$ of $333 \mathrm{mg}-\mathrm{min} / \mathrm{m}^{3}$ for agent GB would be equivalent to $11 \mathrm{mg} / \mathrm{m}^{3}$ for $30 \mathrm{~min}$, or $5.6 \mathrm{mg} / \mathrm{m}^{3}$ for $60 \mathrm{~min}$, or $2.8 \mathrm{mg} / \mathrm{m}^{3}$ for 2 hours. The accuracy of extrapolations for exposure durations in excess of 2 hours is unknown (Grotte and Yang 2001). 


\section{CONCLUSIONS}

- Percutaneous vapor concentrations needed to produce adverse effects are significantly greater than inhalation vapor concentrations necessary to produce the same effect (for nerve agents especially, and sulfur mustard to a lesser extent). Thus, health-based inhalation and ocular toxicity guidelines used to test adequacy of respiratory protection would be substantially protective for percutaneous vapor effects from the same agent exposure. However, use of overly protective inhalation and ocular toxicity criteria for $\mathrm{CPE}$ evaluation may unnecessarily limit consideration of other critical CPE operational specifications. Application of separate toxicity guidelines for percutaneous vapor absorption alone will ensure that CPE testing criteria include an appropriate balance of protection against agent percutaneous toxicity and other necessary operational requirements.

- The application of a preliminary ensemble evaluation screen to eliminate those designs and individual ensembles exhibiting gross defects or breaches would allow greater efficiency, statistical power, and focus on appropriate systems tests.

- Animal data indicate that there is not a significant difference in HD-induced skin damage between males and females; additionally, there do not appear to be substantial differences in cutaneous response on the basis of race (e.g., dark versus light skin).

- The most significant source of variation in susceptibility to percutaneous absorption of CW agents and their simulants is individual body region variation, relative to body site and skin thickness. Thus, selection of appropriately protective CPE designs and materials based on differential body region susceptibility to agent vapor exposures is appropriate.

- With the operating assumption that responders in an agent vapor atmosphere will be wearing SCBA with full-face protection, functional impairment will more rapidly follow from CW agent vapor exposure to the groin and scrotal area than from any other body region. This finding is particularly critical for consideration of operationally adverse exposures to the vesicant agent sulfur mustard (HD).

- Other vulnerable body regions include the neck, scalp, axillae, and area behind the knee (See Tables 1 and 2 of this report)

- Until more agent-specific data become available, toxicological parameters developed for vesicant agent HD may apply to vesicant agent $\mathrm{H}$ (Levinstein mustard) and agent L (Lewisite).

- Nerve agents under consideration are non-irritating to the skin, and generate no cutaneous injuries. Biomarker assessments for these agents as described in NRC/BAST 1997 may be used in conjunction with CPE permeation tests.

- Existing military percutaneous vapor toxicity estimates (IDA Report of Grotte and Yang 2001) are not appropriate for assessment of CPE to be worn by the civilian workforce. Specifically, effects at the concentration-time cumulative exposure toxicity estimates for expected severe effects in $50 \%$ of the exposed population [ECt $\mathrm{EC}_{50}$ (severe)] are too severe. The $50 \%$ threshold effect $\left[\mathrm{ECt}_{50}\right.$ (threshold)] levels represent more reasonable health endpoints, but are still effect levels for $50 \%$ of those exposed, as opposed to levels protecting the majority (if not all) of the exposed population. In addition, existing estimates alone neither address database gaps and uncertainties nor, more importantly, body region variation in absorption and susceptibility.

- Existing percutaneous toxicity data do not comprehensively support any clear, compound-specific, procedure for extrapolating or adjusting $\mathrm{ECt}_{50}$ (threshold) levels to minimal effect levels. 
However, four extrapolation methods developed and evaluated in the present analysis produce estimates all within the same order of magnitude. The most reasonable approaches consider chemical- and effect-specific factors as well as consideration of the agent-specific dose-response curve as defined by the probit slope.

- The state of the modeling tools presently available for percutaneous toxicity estimation is such that discrimination cannot be made between concentrations of concern for exposure durations between 30 and $50 \mathrm{~min}$. It is recommended that, for a given endpoint and scenario, the agentspecific percutaneous vapor $\mathrm{Ct}$ be considered a constant for exposure durations between $30 \mathrm{~min}$ and 2 hours. 


\section{RECOMMENDATIONS}

Selection of appropriately protective CPE designs and materials includes a variety of test parameters to ensure operability, practicality, and adequacy. One aspect of adequacy assessment should be based on systems tests, with primary focus on effective protection of the most vulnerable body regions (e.g., groin and scrotal area) identified in the above analysis.

In conjunction with weighted consideration towards more susceptible body regions, the range of agent-specific Cts (see Table 6) bounded by the estimated minimal effect $\left(\mathrm{EME}_{\mathrm{pv}} \mathrm{Ct}\right.$ ) level and the threshold $\mathrm{ECt}_{01}$ extrapolated from Grotte and Yang (2001) can be used as toxicity guidelines for evaluating and determining CPE acceptance. An example of how these toxicity guidelines may be applied is provided for sulfur mustard (HD), the agent of most significant importance for this testing: In challenge tests of CPE designs, permeation or breach in the groin area of vapor at a $\mathrm{Ct}$ greater than the $3 \mathrm{mg}-\mathrm{min} / \mathrm{m}^{3} \mathrm{EME}_{\mathrm{pv}}$ but less than the $4.1 \mathrm{mg}-\mathrm{min} / \mathrm{m}^{3}$ threshold $\mathrm{ECt}_{01}$ estimate (for hot temperature) over a 30-min exposure duration would be sufficient grounds for ensemble rejection. For other less susceptible body areas (e.g., arms, legs, chest, etc), permeation below the $4.1 \mathrm{mg}-\mathrm{min} / \mathrm{m}^{3}$ threshold $\mathrm{ECt}_{01}$ should be a minimum standard; i.e., exceeding the threshold $\mathrm{ECt}_{01}$ estimate in any test for any body region should be grounds for ensemble rejection.

Assumptions of exposure duration used in CPE certification should consider that the agent-specific percutaneous vapor $\mathrm{Ct}$ for a given endpoint is a constant for exposure durations between $30 \mathrm{~min}$ and 2 hours.

Table 6. Recommended CPE percutaneous vapor toxicity test ranges for nerve agents (GA, GB, GD, GF, VX) and sulfur mustard (HD) (units in $\mathrm{mg}-\mathrm{min} / \mathrm{m}^{\mathbf{3}}$ )

\begin{tabular}{|c|c|c|}
\hline Agent & $\begin{array}{l}\text { Upper end of range: } \\
\text { ECt }_{01} \text { (threshold) estimate }\end{array}$ & $\begin{array}{l}\text { Lower end of range: } \\
\text { est. min. effect }\left(\mathrm{EME}_{\mathrm{pv}} \mathrm{Ct}\right)^{c}\end{array}$ \\
\hline GA & 685 & 333 \\
\hline GB & 411 & 180 \\
\hline GD & 123 & 45 \\
\hline GF & 103 & 45 \\
\hline VX & 4.1 & 4 \\
\hline HD (hot temp.) & 4.1 & 3 \\
\hline \multicolumn{3}{|c|}{$\begin{array}{l}{ }^{a} \text { Based on probit extrapolation of } \mathrm{ECt}_{50} \text { (threshold) from Grotte and Yang } 2001 \text { (see Table } 5 \\
\text { above). }\end{array}$} \\
\hline \multicolumn{3}{|c|}{${ }^{b}$ For susceptible body regions, e.g., groin, scrotal area. } \\
\hline${ }^{c}$ See Table 4 abov & and derivation. & \\
\hline
\end{tabular}




\section{REFERENCES}

ACGIH (American Conference of Governmental Industrial Hygienists). 2000. Threshold Limit Values and Biological Exposure Indices. ACGIH, Cincinnati, $\mathrm{OH}$.

Augerson, W. S. 2000. A Review of the Scientific Literature as It Pertains to Gulf War Illnesses. Vol 5: Chemical and Biological Warfare Agents. RAND Corporation. Available online at http://www.rand.org/publications.

Bartek, M. J., J. A. LaBudde, and H. I. Maibach. 1972. "Skin permeability in vivo: Comparison in rat, rabbit, pig, and man.” J. Investig. Dermatol. 58, 114-123.

Belmonte, R. B. 1998. Test Results of Level A Suits to Challenge by Chemical and Biological Warfare Agents and Simulants: Summary Report. Unclassified Report AD A353013. U.S. Army Edgewood Research, Development and Engineering Center, Aberdeen Proving Ground, MD (August).

Blewett, W. 1986. "Is mustard still king?” NBC Defense Technol. 1, 64-66

Craig, F. N., E. G., Cummings, and V.M. Sim. 1977. "Environmental temperature and the percutaneous absorption of a cholinesterase inhibitor, VX." J. Investig. Dermatol. 68, $357-$ 361.

Cresthull, P., W. S. Koon, N. P. Musselman, M. Bowers, and F. W. Oberst. 1963. Percutaneous Exposure of the Arm or the Forearm of Man to VX Vapor (U). CRDLR 3176; AD 338097. U.S. Army Chemical Research and Development Laboratories Technical Report, Edgewood Arsenal, MD.

Dick, I. P., and R. C. Scott. 1991. "Pig ear skin as an in vitro model for human skin permeability." J. Pharm. Pharmacol. 44, 640-645.

Dixon, M., and D. M. Needham. 1946. "Biochemical research on chemical warfare agents." Nature 158, 432-438.

Duncan, E. J. S., A. Brown, P. Lundy, T. W. Sawyer, M. Hamilton, I. Hill, and J. D. Conley. 2002. "Site-specific percutaneous absorption of methyl salicylate and VX in domestic swine." $J$. Appl. Toxicol. 22, 141-148.

Fedele, P., and D. Nelson. 1996. "The Body Region Hazard Assessment Process." Paper presented before NRC/BAST Standing Committee on Program and Technical Review of the U.S. Army Chemical and Biological Defense Command, at the Edgewood Research Development and Engineering Center, Aberdeen Proving Ground, MD (December 12)

Feinsilver, L., W. M. Lawson, C. V. Lisle, and J. C. Atkinson. 1965. Some Aspects of Percutaneous Penetration of VX in Man. U.S. Army Edgewood Arsenal, Chemical Research and Development Laboratories Technical Report CRDLR 3251 (AD 461572), Edgewood Arsenal, MD.

Gilchrist, H. L. 1928. A Comparative Study of World War Casualties from Gas and Other Weapons. U.S. Government Printing Office, Washington, D.C. (p. 29).

Goldman, M., and J. Dacre. 1989. "Lewisite: Its chemistry, toxicology, and biological effects." Rev. Environ. Contam. Toxicol. 110, 75-115. 
Griesemer, R. D., I. H. Blank, and E. Gould. 1958. "The penetration of an anticholinesterase agent (sarin) into skin. III. A method for studying the rate of penetration into the skin of the living rabbit." J. Invest. Dermatol. 31, 255-258.

Grotte, J. H., and L. I. Yang. 2001. Report of the Workshop on Chemical Agent Toxicity for Acute Effects. Institute for Defense Analyses, May 11-12, 1998. IDA Document D-2176, Institute for Defense Analyses (IDA), 1801 N. Beauregard St., Alexandria, VA (June).

Guy, R. H., and H. I. Maibach. 1984. "Correction factors for determining body exposure from forearm percutaneous absorption data." J. Appl. Toxicol. 4, 26-28.

Heinen, J. H., H. W. Carhart, W. H. Taylor, B.N. Stolp, J. C. Conner, Jr., and N. M. Clausen. 1945. Chamber Tests with Human Subjects. IV. Basic Tests with H Vapor. Naval Research Laboratory Report NRL-P2579 (AD 396275025), Washington, D.C. (duplicated, in part, in Appendix D. "Excerpts from Chamber Tests with Human Subjects I, II and IX. Naval Research Laboratory Reports Nos. P-2208 and P-2579.” pp. 340-369 of IOM 1993).

IOM (Institute of Medicine). 1993. Veterans at Risk: The Health Effects of Mustard Gas and Lewisite. C. M. Pechura and D. P. Rall (eds.), Institute of Medicine, Division of Health Promotion and Disease Prevention, Committee to Survey the Health Effects of Mustard Gas and Lewisite. National Academy Press, Washington, D.C.

Kleinbaum, D. G., L. L. Kupper, and K. E. Muller (eds.). 1988. Applied Regression Analysis and Other Multivariable Methods. 2nd ed. University of North Carolina at Chapel Hill, PWS Kent Publishing Co., Boston.

Maibach, H. I., R. J. Feldman, T. H. Milby, and W. F. Serat. 1971. "Regional variation in percutaneous penetration in man." Arch. Environ. Health 23, 208-211.

McNamara, B. P., E. J. Owens, M. K. Christensen, F. J. Vocci, D. F. Ford, and H. Rozimarek. 1975. Toxicological Basis for Controlling Levels of Mustard in the Environment. Edgewood Arsenal Special Publication, EB-SP-74030. Biomedical Laboratory, Dept. of the Army, Headquarters, Edgewood Arsenal, Aberdeen Proving Ground, MD.

McPhail, M. K., and P. A. Adie. 1960. "Penetration of radioactive isopropyl methylphosphonofluoridate (sarin) vapor through skin.” Can. J. Biochem. Physiol. 38, 935944.

Moody, R. P., and C. A. Franklin. 1987. "Percutaneous absorption of the insecticides fenitrothion and aminocarb." J. Toxicol. Environ. Health 20, 209-218.

Momeni, A. Z., S. Enshaeih, M. Meghdadi, and M. Amindjavaheri. 1992. "Skin manifestations of mustard gas: A clinical study of 535 patients exposed to mustard gas." Arch. Dermatol. 128, 775-780.

Munro, N. B., K. R. Ambrose, and A. P. Watson. 1994. "Toxicity of the organophosphate chemical warfare agents GA, GB and VX: Implications for public protection." Environ. Health Persp. 102, $18-38$.

Nagy, S. M., C. Columbic, W. H. Stein, J. S. Fruton, and M. Bergman. 1946. "The penetration of vesicant vapors into human skin." J. Gen. Physiol. 29, 441-469.

NRC/BAST (National Research Council, Board on Army Science and Technology). 1997. Technical Assessment of the Man-In-Simulant Test (MIST) Program: Assessment of the U.S. Army Chemical and Biological Defense Command. Standing Committee on Program and Technical Review of the U.S. Army Chemical and Biological Defense Command, Board on Army Science and Technology, National Research Council. National Academy Press, Washington, D.C. 
NRC/COT (National Research Council, Committee on Toxicology). 1997. Review of Acute Human-

Toxicity Estimates for Selected Chemical-Warfare Agents, Subcommittee on Toxicity Values for Selected Nerve and Vesicant Agents, Committee on Toxicology, National Research Council. National Academy Press, Washington, D.C.

NRC/COT (National Research Council, Committee on Toxicology). 2001. Standing Operating Procedures for Developing Acute Exposure Guideline Levels for Hazardous Chemicals. Subcommittee on Acute Exposure Guideline Levels, Committee on Toxicology, National Research Council. National Academy Press, Washington, D.C.

OASD-CBD (Office of the Secretary of Defense -Chemical and Biological Defense). 2001. Memo from A. Johnson-Winegar, Deputy for Chemical/Biological Defense, Assistant to the Secretary of Defense, 3050 Defense Pentagon, Washington, D.C., "Interim Certification of Chemical and Biological Data," for General Distribution from DOD Nuclear and Chemical and Biological Defense Programs (27 December).

Opresko, D. M., R. A. Young, R. A. Faust, S. S. Talmage, A. P. Watson, R. H. Ross, K. A. Davidson, and J. King. 1998. "Chemical warfare agents: Estimating oral doses." Rev. Environ. Contam. Toxicol. 156, 1-183.

Papirmeister, B., C. L. Gross, H. L. Meier, J. P. Petrali, and J. B. Johnson. 1985. "Molecular basis for mustard-induced vesication." Fund. Appl. Toxicol. 5, S134-S149.

Papirmeister, B., A. J. Feister, S. I. Robinson, and R. D. Ford. 1991. Medical Defense against Mustard Gas: Toxic Mechanisms and Pharmacological Implications, CRC Press, Boca Raton, FL.

PCS (Project Coordination Staff). 1946. Technical Aspects of Chemical Warfare in the Field. Part 2. Discussion of Experimental Data. Chemical Warfare Service, Washington, D.C. (as cited in Papirmeister et al. 1991)

Riviere, J. E., C. E. Smith, K. Budsabe, J. D. Brooks, E. J. Olajos, H. Salem, and N. A. MonteiroRiviere. 2001. "Use of methyl salicylate as a simulant to predict the percutaneous absorption of sulfur mustard.” J. Appl. Toxicol. 21, 91-99.

Sidell, F. R. 1992. "Clinical considerations in nerve agent intoxication.” Pp. 155-194 in Chemical Warfare Agents, ed. Somani. Academic Press, New York.

Sidell, F. R. 1997. "Nerve Agents." Chapter 5, pp. 129-179, in Medical Aspects of Chemical and Biological Warfare, ed. F. R. Sidell, A. T. Takafuji, and D. R. Franz. Published by the Office of the Surgeon General, at TBMM Publications, Borden Institute, Walter Reed Army Medical Center, Washington, D.C.

Sim, V. M., and J. L. Stubbs. 1960. VX Percutaneous Studies in Man (U). U.S. Army Chemical Research and Development Laboratories Technical Report, CRDLR 3015, AD 318533, Army Chemical Center, MD.

Sim, V. M. 1962. Variability of Different Intact Human-Skin Sites to the Penetration of VX. U.S. Army Chemical Research and Development Laboratories Technical Report, CRDLR 3122, AD 271163, Army Chemical Center, MD.

Smith, W. J., and M. A. Dunn. 1991. "Medical defense against blistering chemical warfare agents." Arch. Dermatol. 127, 1207-1213.

Smith, W. J. 2002. "Vesicant agents and antivesicant medical countermeasures: Clinical toxicology and psychological implications." Military Psychology 14(2), 145-157. 
Temple, J. W. 1923. Blistering Concentration of Mustard Gas Vapours for Exposures from Five Minutes to Three Hours. War Department, Chemical Warfare Service Report \# EAMRD9, AD B954963, Edgewood Arsenal, Edgewood, MD.

U.S. Congress. 1970. Occupational Safety and Health Act of 1970. Pub. L. 91-596, 84 Stat. 1590, 29 USCA; 651-78.

USDHHS (U.S. Department of Health and Human Services). 2002a. Notice of Meeting; NIOSH Standards Development for Full Facepiece Air-Purifying Respirators (APR) Used to Protect Emergency Response Workers Against Chemical, Biological, Radiological and Nuclear (CBRN) Agents. Centers for Disease Control and Prevention. Federal Register, 67(105), 38127-38128 (31 May).

USDHHS (U.S. Department of Health and Human Services). 2002b. Notice of Meeting; Conceptual Discussions for Full Facepiece Air-Purifying Respirators (APR) Standards and Air-Purifying Escape Respirator Standards Development Efforts for Respiratory Protection against Chemical, Biological, Radiological and Nuclear (CBRN) Agents. Centers for Disease Control and Prevention. Federal Register, 67(188), 61108 (27 September).

van Hooidonk, C. 1978. Percutaneous Absorption of Toxic Agents. II. The Nerve Gases and Some Other Toxic Organophosphates. A Survey of the Literature. Report No. PML-1978-9 (ADBO30141). Prins Maurits Laboratory, TNO, Rijswijk, The Netherlands (January 1978) (in Dutch).

van Hooidonk, C., B. I. Ceulen, J. Bock, and J. van Genderen. 1983. "CW agents and the skin. Penetration and decontamination." Proc. International Symposium of Protection Against Chemical Warfare Agents, Stockholm, Sweden (6-9 June).

Watson, A. P., and G. D. Griffin. 1992. "Toxicity of vesicant agents scheduled for destruction by the Chemical Stockpile Disposal Program.” Environ. Health Persp. 98, 259-280.

Wester, R. C., and H. I. Maibach. 1985. "In vivo percutaneous absorption and decontamination of pesticides in humans." J. Toxicol. Environ. Health 16, 25-37.

Wester, R. C., and H. I. Maibach. 1989. "Regional variation in percutaneous absorption." Chapter 7, pp. 111-119 in Percutaneous Absorption: Mechanisms-Methodology-Drug Delivery, 2nd ed., ed. R. L. Bronaugh and H. I. Maibach. Marcel Dekker, New York.

Wormser, U., B. Brodsky, and A. Sintov. 2002. "Skin toxicokinetics of mustard gas in the guinea pig: Effect of hypochlorite and safety aspects." Arch. Toxicol. 76, 517-522. 
ORNL/TM-2003/180

\section{INTERNAL DISTRIBUTION}

\author{
1. B. A. Berven \\ 2. W. F. Harris \\ 3-7. D. M. Opresko
}

8-17. A. P. Watson

25. Laboratory Records-RC

26. Central Research Library

\section{EXTERNAL DISTRIBUTION}

27-50. V. Hauschild, Directorate of Health Risk Management, U.S. Army Center for Health Promotion and Preventive Medicine, Aberdeen Proving Ground, MD. 
